\title{
Selective and taxon-dependent effects of semi-feral cattle grazing on tree regeneration in an old-growth Mediterranean mountain forest
}

\author{
Xavier Fortuny ${ }^{1}$, Christopher Carcaillet ${ }^{1,2}$ and Sandrine Chauchard ${ }^{3 *}$
}

\begin{abstract}
Background: In Mediterranean mountain socio-ecosystems, both grazing by livestock and the dry season may influence tree regeneration. However, the relative contributions of these drivers are poorly known, even though present and future canopy composition might result from past and present variations in climate and herbivore density. This study aims to test how semi-feral cattle presence and season affect tree regeneration.
\end{abstract}

Methods: The study was conducted using permanent plots inside and outside a cattle exclosure in an old-growth Mediterranean forest. Saplings and seedlings were counted five times per year (winter, early spring, middle spring, summer, fall) and monitored over 7 yrs.

Results: Semi-feral cattle exclusion increased Acer, Fagus, Ilex, Pinus, Prunus and Quercus sapling densities and increased Acer, Fraxinus, Ilex, Quercus and Sorbus seedling densities. Interestingly, the dry season did not exert any noticeable effects on the sapling or seedling densities of any of the studied taxa.

Discussion: Semi-feral cattle presence may limit tree regeneration through taxon-dependent effects, which suggests that the current decrease in grazing livestock across the Mediterranean basin will modify recruitment processes and, likely, future forest composition.

Conclusions: Semi-feral cattle presence acts as a selective driver of tree community composition.

Keywords: Cattle, Climate, Experiment, Herbivory, Forest pastoralism

\section{Background}

Summer grazing in Mediterranean mountain areas has historically been an important socio-economical activity, as it provides livestock with essential nutritional supplements during the dry and warm seasons (Casasùs et al. 2007). Although forest grazing is still used by farmers in some areas, the last decades have been characterised by a net decrease in forest pastures across northern Mediterranean countries, a dynamic which is mainly

\footnotetext{
* Correspondence: sandrine.chauchard@univ-lorraine.fr

${ }^{3}$ Université de Lorraine, AgroParisTech, INRAE, UMR Silva, 54000 Nancy,

France

Full list of author information is available at the end of the article
}

explained by the abandonment of low productivity areas that are widespread in mountain regions. However, the consequences of these large-scale land-use changes, which include effects on long-term community diversity, remain unclear. The presence of large domestic mammals may influence the recruitment of species through selection of palatable seedlings and saplings, foraging on competing species, trampling, and modification of organic matter turnover and biogeochemical fluxes (McEvoy et al. 2006; Marquardt et al. 2009; Wassie et al. 2009). The community structure and functioning of forest socio-ecosystems should thus differ based on

(c) The Author(s). 2020 Open Access This article is licensed under a Creative Commons Attribution 4.0 International License, which permits use, sharing, adaptation, distribution and reproduction in any medium or format, as long as you give appropriate credit to the original author(s) and the source, provide a link to the Creative Commons licence, and indicate if changes were made. The images or other third party material in this article are included in the article's Creative Commons licence, unless indicated otherwise in a credit line to the material. If material is not included in the article's Creative Commons licence and your intended use is not permitted by statutory regulation or exceeds the permitted use, you will need to obtain permission directly from the copyright holder. To view a copy of this licence, visit http://creativecommons.org/licenses/by/4.0/. 
whether domestic herbivores are present or not (for a review of effects see Öllerer et al. 2019).

Seedling emergence can be negatively affected by both direct mechanisms, such as the destruction and burial of seeds (Hulme and Borelli 1999; Smit et al. 2006), and indirect mechanisms, such as soil compaction, solifluction and erosion (McEvoy et al. 2006; Wassie et al. 2009). Livestock may also hamper seedling growth and survival via the direct consumption of entire seedlings or their shoots, mainly leaves and buds (Kuiters and Slim 2002; Wassie et al. 2009). However, the magnitude of the impact on species and community structure depends on plants, productivity, grazing system and ungulate density (Plieninger et al. 2004; Teich et al. 2005; Carmona et al. 2013; Chauchard et al. 2018, Ramirez et al. 2018). In some cases, even low livestock density can have consequences for tree demography (Cierjacks and Hensen 2004; Casasùs et al. 2007; Tremblay et al. 2007, Smit et al. 2015). The regeneration impacts attributed to livestock also vary based on grazer characteristics (Marquardt et al. 2009). These differences may stem from both animal diet selection and seedling/sapling species characteristics like compensatory growth ability after defoliation (Kupferschmid 2017). These differences can skew species distributions so that resilient species are favoured over sensitive species. On the other hand, herbivore presence may facilitate seedling emergence, growth and survival by removing competitive or inhibiting plants, e.g. grass and shrubs, or exposing bare ground though trampling, which can create regeneration niches (Kuiters et al. 1996; Perrin et al. 2006).

Studies with a focus on how livestock influence tree regeneration in Mediterranean regions have generally focussed on oaks (e.g. Henkin et al. 2005; Plieninger 2007; Papachristou and Platis 2011), which dominate forests (FAO 2018). Nevertheless, little is known about how semi-feral cattle presence impacts the regeneration of entire tree communities, especially in mixed forests. The present paper describes how grazing by large semi-feral cattle affects tree regeneration in a mixed old-growth Mediterranean mountain forest in which cattle have been present for centuries (Fortuny et al. 2014, 2017). Cattle presence is certainly not the sole factor affecting tree regeneration. For example, the Mediterranean climate is characterised by dryness during summer months - a result from both high temperatures and low precipitation - which is known to hamper seedling establishment (Castro et al. 2005; Mendoza et al. 2009). Water stress, which affects both water use efficiency and carbon allocation, strongly influences seedling survival (Kolb and Robberecht 1996). The issue of water-stress is important to the Mediterranean, as the region is expected to be strongly affected by increased temperatures caused by global warming (Christensen and Christensen
2007). Precipitation is also expected to decrease, and this will be particularly evident during summer months (Giorgi and Lionello 2008). The resulting increase in summer dryness could affect long-term forest productivity (Van der Moelen et al. 2011), as well as the tree recruitment processes and diversity. Dry and hot summers may also be a factor that interacts with cattle grazing. For example, sapling species that are better adapted to the changing climate could also be highly resistant to herbivory. In this case, the effect of summer dryness would override the grazing effect.

The study aims to test the effects of semi-feral cattle presence and season on tree regeneration through experiments that excluded cattle using permanent plots. The experiments investigated two components of tree regeneration: the number of seedlings and the number of saplings available for regeneration (Arista 1995). We hypothesise that (1) semi-feral cattle presence reduces regeneration potential, yet this driver of community composition varies between tree species, and (2) stressful summer conditions and cattle presence have a combined negative effect on tree regeneration. Because grazing by cattle is decreasing locally and climate change is expected to exert significant effects, this study may help highlight future consequences for tree regeneration in Mediterranean mountain socio-ecosystems.

\section{Methods \\ Study area}

The study was carried out in the Massane Natural Reserve $\left(42.5^{\circ} \mathrm{N}, 03.0^{\circ} \mathrm{E}\right)$, which covers the whole upper valley of the Massane River in the Albères Massif of the eastern French Pyrenees (Supplementary material S1). The southern crests of the upper valley mark the French-Spanish border. The valley has an altitude ranging from 600 to $1200 \mathrm{~m}$ above sea level (a.s.l.) and is characterised by generally steep slopes (ca. $40^{\circ}$ ). The bedrock is composed of acidic shale and gneiss, and the soil belongs to the brunisol category (Servant 1970). The area has a typical Mediterranean mountain climate, with warm and dry summers and cool and windy winters (Garrigue and Magdalou 2010). Mean annual precipitation is $1140 \pm 327 \mathrm{~mm}$ (period 1976-2017, meteorological station in the Massane Nature Reserve [NR]), with the rain mainly concentrated to the spring and autumn. The dry season occurs between June and August (with mean monthly precipitation of $37 \pm 26 \mathrm{~mm}, 31 \pm$ $27 \mathrm{~mm}$ and $33 \pm 19 \mathrm{~mm}$, respectively, between 1976 and 2017). Mean annual temperature (1976-2017) is $11.9 \pm$ $1.0^{\circ} \mathrm{C}$, with January $\left(5.1 \pm 1.7^{\circ} \mathrm{C}\right)$ and July $\left(20.1 \pm 1.8^{\circ} \mathrm{C}\right)$ as the coldest and warmest months, respectively.

The valley includes two ecological zones: forests and woodlands below $900-1000 \mathrm{~m}$ a.s.l., and grassland on the crests. Forests cover over $50 \%$ of the NR. The forest type 
is dominated by beech (Fagus sylvatica L.) with other broad-leaved trees present, namely, white oak (Quercus pubescens Willd.), whitebeam (Sorbus aria L.), wild cherry-tree (Prunus avium L.), maples (Acer campestre L., A. monspessulanum L., A. opalus Mill.) and holm oak (Q. ilex L.). Individual occurrences of ash tree (Fraxinus excelsior L., F. angustifolia Vahl), Austrian black pine (Pinus nigra subsp. nigra Arn.) and yew (Taxus baccata L.) are scattered throughout the reserve. The understory is dominated by European holly (Ilex aquifolium L.). The Austrian pine was introduced and naturalised during the nineteenth century (Chauchard et al. 2006).

The upper Massane valley (336 ha) was designated as a NR in 1973, but was already protected since the early 1950's. A French NR entails high protection status (category IV and category 1a, UICN) that bans economic exploitation (except traditional activities with little impact on species and their habitats, e.g. pastoralism) and most recreational activities like hunting and fishing. Approximately 10 ha of the inner forest zone has been fenced off since 1954 to exclude cattle (category 1a, UICN). The fence consists of wire netting $1.10 \mathrm{~m}$ in height (meshsize of $10 \mathrm{~cm}$ ) with no anchor in the soil. The rest of the reserve (category IV, UICN) is browsed and grazed by semi-feral cattle (Bos taurus L.). Wild boar (Sus scrofa L.) and roe deer (Capreolus capreolus L.) are the only other two wild large herbivores that have been recorded in the forest. A permanent roe deer population does not currently exist in this mountain massif. Even though no quantitative data about these two wild ungulates are available, their impacts on tree regeneration were considered negligible because the estimated densities of both herbivores in the area were low.

The semi-feral cattle can freely enter the higher altitudes at the beginning of the spring (post-calving period) and then remain there until autumn. During these five to six months they browse and graze freely. Some cattle, generally bulls, are present in the area even during winter months, but at very low densities. During the sampling period, cattle were present at noticeably different densities in the winter $\left(\sim 0.08\right.$ heads.ha $\left.{ }^{-1}\right)$ and spring-summer $\left(0.46\right.$ heads $\left.\mathrm{ha}^{-1}\right)$. Cattle densities, provided by the NR administration, can be influenced by an unknown number of erratic cattle that enter the area from the south-facing slopes of the mountain massif (i.e., Spanish side) to visit the fresher north-facing slopes, including the Natural Reserve. This occurrence of erratic cattle was mainly noted during the hot and dry summer months, which make the south-facing slopes more arid, and affect the crest grasslands and upper forest more than the lower forests in which the experimental site was situated. Even though the exact number of erratic cattle cannot be reliably quantified, this occurrence has little influence on the cattle density observations provided by the NR administration.

\section{Experimental design}

Four permanent $50 \mathrm{~m}^{2}\left(1 \mathrm{~m} \times 50 \mathrm{~m}\right.$; total $\left.200 \mathrm{~m}^{2}\right)$ transects were established in the forest in 2006 (Table 1) and monitored until 2012. The mean distance between each transect was about $190 \pm 104 \mathrm{~m}$, and the transects were established at altitudes ranging from 661 to $728 \mathrm{~m}$ a.s.l. The transect locations were chosen based on two criteria: (1) minimal risk of disturbances like runoff and soil erosion; and (2) a site that is representative of the main forest microhabitats. Transect 1 ( $\operatorname{Tr} 1)$, near the river, is in the wettest part of the forest. Transect $2(\mathrm{Tr}$ 2 ) is located in a patchy population of pine mixed with beeches and white oaks. Transects 3 and 4 are located in the main part of the forest, i.e. more homogeneous and mainly dominated by beech trees of different ages and shapes ( $\operatorname{Tr} 3$ : taller and younger; $\operatorname{Tr} 4$ : smaller but older trees).

Each transect was divided into two $25 \mathrm{~m}^{2}(1 \mathrm{~m} \times 25 \mathrm{~m})$ sub-transects: one was located in a single cattle exclosure (fenced area) from which cattle have been excluded since 1954, while the second was located in an unfenced area. Thus, four of the eight sub-transects were located in the same cattle exclosure. The sub-transects (inside and outside the fence) of each transect included equivalent environmental conditions. The mean distance between each sub-transect was around $20 \mathrm{~m}$. A $1 \mathrm{~m} \times 1 \mathrm{~m}$ quadrat was used to count the seedlings and saplings in each transect. The quadrat was sub-divided into a hundred $10 \mathrm{~cm} \times 10 \mathrm{~cm}$ sub-quadrats that allowed the monitoring of individual seedlings over the course of the year. In total, 20,000 sub-quadrats with an area of $100 \mathrm{~cm}^{2}$ were monitored.

Between 2006 and 2012, tree seedlings and saplings in each of the 20,000 sub-quadrats were counted five times per year: late winter (March-April transition); early spring (April-May transition); middle spring (May-June transition); early summer (June-July transition); and early autumn (middle October).

Table 1 Transect description. UNF: unfenced area (grazed), FEN: fenced area (ungrazed)

\begin{tabular}{|c|c|c|c|c|c|c|c|}
\hline \multirow[t]{2}{*}{ Transect } & \multicolumn{2}{|c|}{ Coordinates } & \multirow{2}{*}{$\begin{array}{l}\text { Altitude } \\
\text { (m, } \\
\text { a.s.l.) }\end{array}$} & \multirow{2}{*}{$\begin{array}{l}\text { Slope } \\
\left({ }^{\circ}\right)\end{array}$} & \multicolumn{3}{|c|}{ Vegetation cover (\%) } \\
\hline & Long. ( $\left.{ }^{\circ} \mathrm{E}\right)$ & Lat. ( $\left.{ }^{\circ} \mathrm{N}\right)$ & & & Tree & Shrub & Grass \\
\hline JNF & 3. & 42 & 661 & 18 & 0 & $5-25$ & $5-25$ \\
\hline EN & 30726 & 42.48 & 661 & 25 & $25-50$ & $5-25$ & $50-75$ \\
\hline UNF & 3.03001 & 42.48741 & 713 & 22 & $50-75$ & $<5$ & $5-25$ \\
\hline 2 FEN & 3.02992 & 42.48748 & 713 & 22 & $50-75$ & $<5$ & $25-50$ \\
\hline UNF & 3.03137 & 42.48895 & 728 & 16 & $50-75$ & $<5$ & $<5$ \\
\hline 3 FEN & 3.03083 & 42.48892 & 711 & 20 & $50-75$ & $<5$ & $25-50$ \\
\hline UNF & 3.03230 & 42.49102 & 689 & 17 & $50-75$ & $<5$ & $5-25$ \\
\hline 4 FEN & 3.03206 & 42.49111 & 697 & 21 & $50-75$ & $5-25$ & $25-50$ \\
\hline
\end{tabular}


This study considers both first-year seedlings, hereafter "seedlings", and saplings over a year old and $<20$ $\mathrm{cm}$ in height. The seedlings can be easily distinguished from the saplings by the presence of cotyledons. Because the study was conducted in a NR, individual marking and tracking was not possible.

While the precipitation levels observed in 2008 and 2012 were close to historical levels, they were lower than average in 2006, 2007 and 2009 (Fig. 1a). The summers of 2006 and 2009 were hot and dry whereas the summer of 2007 was only dry (Fig. 1b and c). In 2009, the autumn and spring were also dry (Fig. 1b). The precipitation levels observed in 2010 and 2011 were higher than average, with 2010 and 2011 showing very wet spring and autumn periods (Fig. 1b). These observations translate to high inter-annual variability in seasonal features.

\section{Data analyses}

The community structure of the seedlings and saplings were investigated in the first step of the analyses. During the second step, we analysed the effect of semi-feral catthe presence and season on seedling and sapling density (individual no. per $\mathrm{m}^{2}$ ). The observed tree seedling and sapling densities of Acer sp., Fagus sylvatica, Fraxinus sp., Ilex aquifolium, Pinus nigra, Prunus avium, Quercus pubescens and Sorbus aria were included in the analyses. The seedling and sapling densities of Quercus ilex and Taxus baccata were excluded because these species showed extremely low abundance. The three species of maple were analysed at the genus level because a high level of hybridization makes seedling identification at the species level almost impossible. The ash seedlings were also analysed at the genus level because $F$. excelsior and F. angustifolia seedlings are difficult to differentiate.

\section{Community analysis}

The relationships between seedling and sapling community structures and the explanatory variables (transect, year, season, fencing) were assessed by a constrained ordination of the seedling and sapling counts data using
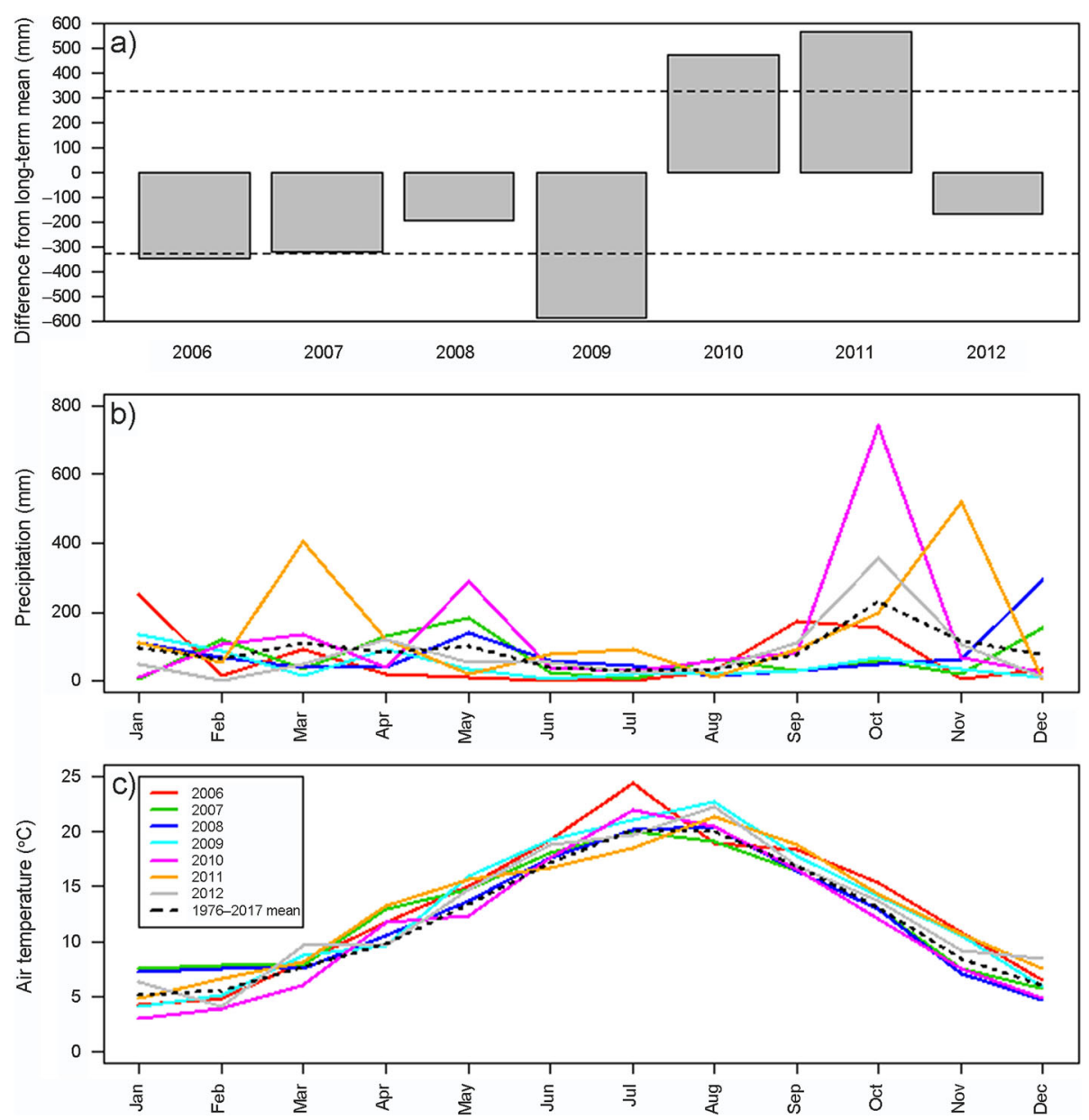

Fig. 1 (a) Precipitation anomalies for the experimental period 2006-2012 relative to historical average (1140 mm, 1976-2017); horizontal dashed lines indicate standard deviations (327 mm). Monthly total precipitation (b) and average air temperature (c) for 2006, 2007, 2008, 2009, 2010, 2011, 2012, with the historical values (1976-2017) shown for comparison 
redundancy analysis (RDA). This analysis was performed using the package "vegan" (Oksanen et al. 2019). The RDA response matrix was a taxa matrix composed with the data records as rows and the eight taxa as columns. Each record in this matrix corresponded to the seedling and sapling count combined in each sub-transect, for each sampling season, over the study duration. A Hellinger pre-transformation of the data was performed (Legendre and Gallagher 2001). In this transformation, the abundance values were first divided by total recorded abundance, after which the result was square-root transformed. After the first RDA, a forward selection was run using the ordiR2step function (package "vegan", Oksanen et al. 2019) by permutation tests based on adjusted $R^{2}$ using 199 permutations. The model that maximized the adjusted $R^{2}$ was retained. Transect, year, season and fencing contributions to seedling and sapling community structures were then assessed through variance partitioning.

Due to variability in tree regeneration between years, which was particularly evident in species or taxa that show masting years (Fagus sylvatica, Quercus pubescens and Fraxinus excelsior), and the strong effect of each transect's forest canopy on seedling taxa composition, a conditioned RDA was performed to isolate the effects of cattle presence and season from the effects of year and transect (which were not considered in the analysis). To facilitate the visualisation of RDA results, records were clustered in term of classes in the scatter diagrams. Each cluster groups records that belong to a specific transect and the sub-transect (fenced or grazing area).

\section{Effect of cattle presence and season on seedling and sapling density}

A generalised linear mixed-effect model (GLMM), which allowed crossed random effects and employed a negative binomial distribution and a log-ratio link function (package "lme4", Bates et al. 2015), was used to test how the interaction between taxa and semi-feral cattle presence (inside versus outside the fenced area) and the interaction between taxa and season (winter, early spring, middle spring, early summer and autumn) affected seedling density, sapling density and overall seedling and sapling density. Count data were generally analysed using Poisson distributions, but when variance exceeded the mean (overdispersion) negative binomial distributions were preferred (Krebs 1999). The interactions between taxa and years (taxon: year) and between taxa and transects (taxa: transect) were included as crossed random effects in the GLMM model. This is because transects and years had varying effects on different taxa over the study period.

The GLMM was tested for over-dispersion using the "blmeco" package (Korner-Nievergelt et al. 2015), using
$\Phi>0.7$ and $\Phi<1.4$ as thresholds for potential overdispersion. The normality of residuals was visually checked using a histogram and normal $\mathrm{q}-\mathrm{q}$ plot. We also checked that the residuals are centred around zero throughout the range of fitted values. We used the dredge function in the "MuMln" package (Barton 2019), which automatically fits all of the different combinations of fixed predictor variables to the data and calculates Akaike Information Criterion (AIC) values, to identify the optimal model. The subset of models identified for the input data were then used to calculate the final model. The "MuMln" package was also used to calculate marginal $R^{2}$ (representing only fixed effects) and conditional $R^{2}$ (representing both fixed and random effects) so that we could determine how much of the variation was explained by fixed and random effects, respectively (Nakagawa and Schielzeth 2013). The significance of fixed effects in the best model was assessed by Waldtests applying $X^{2}$ probabilities in the "car" package (Fox and Weisberg 2019). Post-hoc tests, predicted marginal means, and standard errors for fixed effects were calculated using the "lsmeans" package (Lenth 2016).

\section{Results}

The densities of seedlings and saplings varied according to taxa. Fagus sylvatica was the dominant taxon of the regeneration community, representing, on average, around $44 \%$ of the saplings and $25 \%$ of the seedlings in the fenced area (Supplementary material S2). The second most abundant taxon was Ilex aquifolium, which corresponded to $27 \%$ and $25 \%$ of the saplings and seedlings in the fenced area, respectively (Supplementary material S2). Seedling and sapling densities also varied between years (Supplementary material S2). Intra-annual variations in seedling and sapling density, which were mainly linked to differences between transects, were also important (Supplementary material S2).

\section{Community structure}

The redundancy analysis (RDA) model that maximised adjusted $R^{2}$ included transect, year and cattle exclosure (fencing) but did not include season (adj. $R^{2}=0.45$ ). In this model, transect, year and fencing explained $49.9 \%$, $9.7 \%$ and $2.1 \%$ of the variance, respectively. The first two RDA axes captured $49.8 \%$ of the variance (Fig. 2a). The first RDA axis (36.4\% of the total variance) separated Fagus sylvatica and Pinus nigra (positive values) from Acer sp. (negative values). The second RDA axis (13.4\% of the total variance) included Quercus pubescens on the positive side. Fraxinus sp. was located on the negative sides of both axes 1 and 2. Ilex aquifolium demonstrated negative and positive values for axes 1 and 2, respectively. The first RDA axis isolated: i) transect 1 (high abundance of Fraxinus, Ilex and Acer) on the negative 


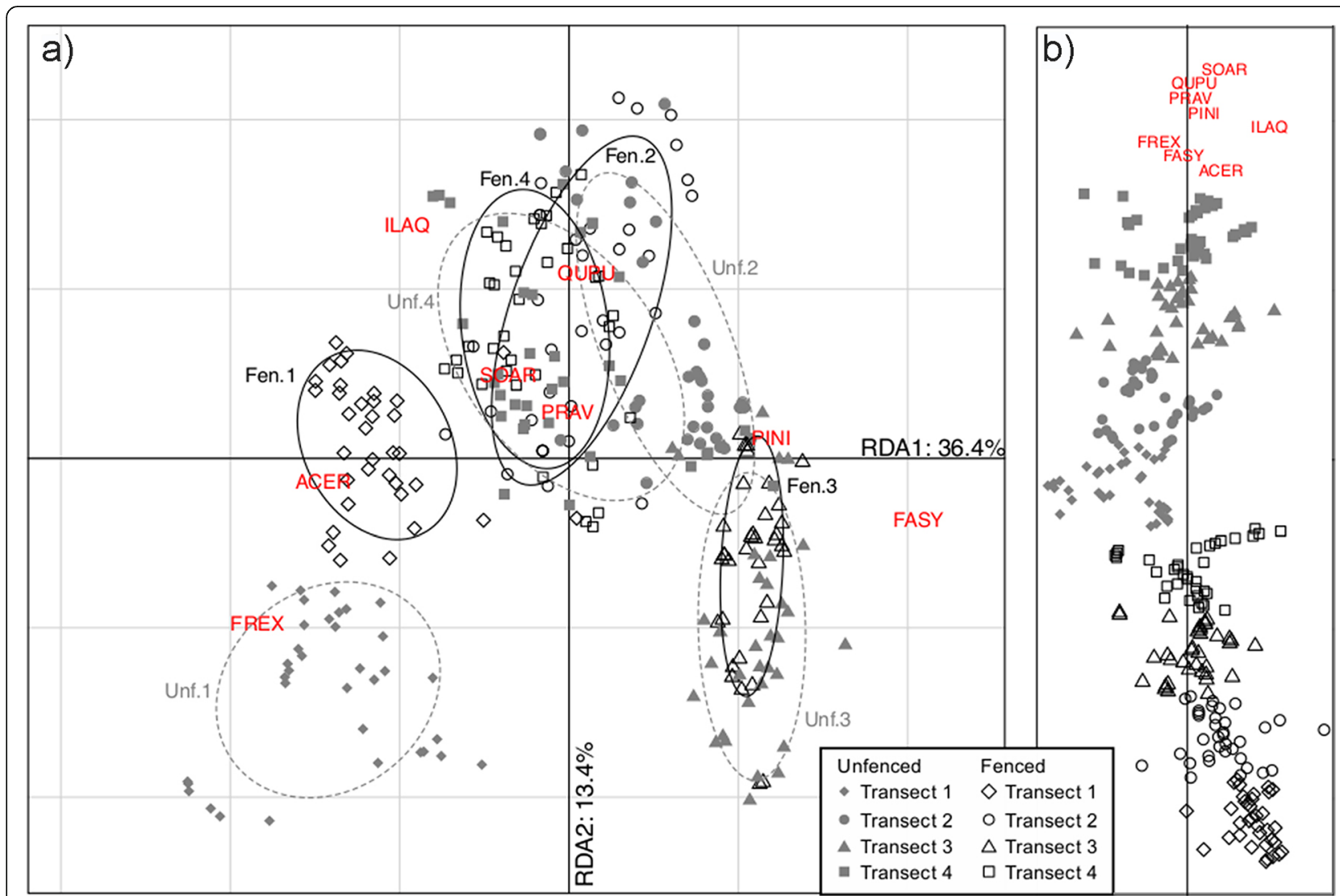

Fig. 2 (a) Redundancy analysis (RDA) ordination diagram of both seedling and sapling communities, with a scatter diagram of sample scores clustered in terms of transect number and livestock presence (unfenced vs fenced). FASY: Fagus sylvatica; QUPU: Quercus pubescens; SOAR: Sorbus aria; PRAV: Prunus avium; ACER: Acer sp.; FREX: Fraxinus sp.; PINI: Pinus nigra; ILAQ: Ilex aquifolium; Unf: unfenced area (presence of semi-feral cattle); Fen: fenced area (absence of semi-feral cattle); 1 to 4: transect number. The ellipses correspond to confidence intervals of $1.5 \times$ standard deviation for the average coordinates of samples. (b) Scores along the first axis of a conditioned redundancy analysis ordination (horizontal axis) diagram of seedling and sapling communities that only includes the effect of cattle presence (the effects of transect and year were excluded)

side of the plot; and ii) transect 3 (high abundance of Fagus and Pinus) on the positive side of the plot. When interpreting the second RDA axis, we noticed that coordinates representing the cattle exclosures of $\operatorname{Tr} 1$ and $\operatorname{Tr}$ 3 were located noticeably higher on the plot than the coordinates from unfenced areas of the same transects. The coordinates for the other two transects (2 and 4) did not differ noticeably based on whether they represented fenced or unfenced areas.

After removing transect and year effects, the conditioned RDA axis (including only cattle presence) explained $5.5 \%$ of the total variance (Fig. $2 \mathrm{~b}$ ). The conditioned RDA axis clearly isolated the cattle exclosure sub-transects (positive values, and associated with a higher abundance of Ilex, Acer and Sorbus) from the unfenced sub-transects (negative values).

\section{Effect of cattle presence versus season on density}

The best regression model for overall seedling and sapling densities included interaction between taxon and cattle presence ('taxon:fence', Table 2), while interaction between taxon and season ('taxon:season') was excluded.

Table 2 General linear mixed models (GLMM) for overall seedling and sapling densities, seedling density and sapling density. Only the results of the best models are displayed. 'Taxon:Fence': interaction between taxa and cattle presence; 'Taxon:Season': interaction between taxa and season. $R_{\mathrm{m}}^{2}$ : marginal $R^{2}$ (fixed effects only), $R_{c}^{2}$ : conditional $R^{2}$ (fixed and random effects)

\begin{tabular}{|c|c|c|c|c|c|c|c|c|c|}
\hline & \multicolumn{3}{|c|}{ Seedling + Sapling $\left(R_{\mathrm{m}}^{2}=0.36, R_{c}^{2}=0.85\right)$} & \multicolumn{3}{|c|}{ Seedling $\left(R_{\mathrm{m}}^{2}=0.30, R_{\mathrm{c}}^{2}=0.78\right)$} & \multicolumn{3}{|c|}{ Sapling $\left(R_{\mathrm{m}}^{2}=0.44, R_{\mathrm{c}}^{2}=0.87\right)$} \\
\hline & Chisq & Df & $\operatorname{Pr}(>$ Chisq) & Chisq & Df & $\operatorname{Pr}(>$ Chisq) & Chisq & Df & $\operatorname{Pr}(>$ Chisq) \\
\hline Taxon: Fence & 197.5 & 15 & $<0.001$ & 80.9 & 15 & $<0.001$ & 357.8 & 15 & $<0.001$ \\
\hline Taxon: Season & - & - & - & 214 & 32 & $<0.001$ & 80.7 & 32 & $<0.001$ \\
\hline
\end{tabular}


Cattle presence significantly affected the overall seedling and sapling density (SSD) of Acer, Fagus, Fraxinus, Ilex, Prunus, Quercus and Sorbus (Figs. 3a, b and 4a). Transects within cattle exclosures showed higher seedling and sapling densities than transects outside of exclosures (Figs. 3a, b and 4a). The extent to which cattle presence affected SSD differed between species, namely, Acer, Ilex, Quercus and Sorbus regeneration was more affected by cattle presence than the regeneration rates observed for Fagus, Fraxinus and Prunus (Fig. 4a).

The best regression model for seedling densities included both 'taxon:fence' and 'taxon:season' interactions (Table 2). Cattle presence significantly affected Acer, Fraxinus, Ilex, Quercus and Sorbus seedling density (Figs. $3 \mathrm{c}, \mathrm{d}$ and $4 \mathrm{~b}$ ). Each of these five taxa showed significantly higher seedling densities within cattle exclosures than in unfenced areas (Figs. 3c, d and 4b). However, the extent to which cattle presence affected seedling density varied between taxa: Quercus and Sorbus were the most affected, showing slightly higher marginal mean differences than Ilex and Acer, while Fraxinus seedling densities were the least affected by cattle presence (Fig. 4b). The interaction 'taxon:season' also had a significant effect on seedling density (Table 2). These effects were not linked to the dry season, but rather seedling emergence, which occurs between late winter and early spring for all taxa (Fig. 5a).

The best regression model for sapling densities included both 'taxon:fence' and 'taxon:season' interactions (Table 2). The presence of cattle had a significant effect on Acer, Fagus, Ilex, Pinus, Prunus and Quercus sapling densities (Figs. 3e, f and 4c). Furthermore, sapling densities were generally higher inside the cattle exclosure than in unfenced areas. As was the case for seedling densities, the extent to which cattle presence affected sapling density differed between taxa (Figs. 3e, f and 4c). Acer and Ilex were the most affected, and showed higher marginal mean differences than Fagus, Pinus and Prunus (Fig. 4c). The interaction 'taxon:season' significantly influenced sapling density (Table 2), but no differences between successive seasons were found (Fig. 5c).

\section{Discussion}

The present study reports that semi-feral cattle presence has a selective impact on regeneration of Mediterranean mountain trees due to taxon-specific effects. The dry season (summer) effect was not observed in the analyses, which contrasts our working hypothesis. Although this study does not consider processes that influence juvenile tree survival prior to the adult stage (i.e. recruitment), which can diminish the seedling/sapling stock, the results provide solid evidence for how the current climate and semi-feral cattle presence can affect seedling and sapling densities. These effects are first discussed in terms of tree community and populations dynamics under the effect of grazing, after which the implications for forest conservation management are covered.

\section{The seedling and sapling community structure}

The seedling and sapling communities both showed strong spatial clustering based on transect location, which explained $49.9 \%$ of the observed variance. Spatial heterogeneity can be expected in old Mediterranean mountain forests (e.g., Fournier et al. 2012), and is likely connected to soil thickness, terrain variation or tree cover composition. For instance, transect 1 is close (ca. 25 to $50 \mathrm{~m}$ ) to a winding stream that traverses the $\mathrm{Na}$ ture Reserve. This transect also showed the lowest tree cover $(25 \%-50 \%)$. Seedling composition in the unfenced part of this transect differed strongly from what was observed in other transects, especially in terms of Fraxinus seedlings. Fraxinus trees are more abundant in the riparian forest than in the rest of the forest. Furthermore, Fraxinus is a light-demanding taxon that would be favoured in areas with low tree cover. For both of these reasons, it is not surprising that the unfenced subtransect of transect 1 was dominated by Fraxinus seedlings (Table 1). As the mean distance between pairs of 25 - $\mathrm{m}$ sub-transects was $\sim 20 \mathrm{~m}$, we cannot rule out that edge effects influenced our results. Both sub-transects in each site were at $10 \mathrm{~m}$ from the fence.

Strong variability was observed between the years (SM S2); for example, the year explained $9.7 \%$ of the community variance. The variation observed in seedling densities may be the result of irregular seed production between years; for example, Fagus, Quercus and Fraxinus are known to be masting taxa (Tapper 1996; Piovesan and Adams 2001; Alejano 2011; Vacchiano et al. 2017), which may lead to interannual pollen limitation (Schermer et al. 2019). As highlighted by Alejano (2011), masting clearly influences the regeneration success of trees and the demography of seed consumers. Moreover, the weather can directly impact germination and survival, e.g., extreme precipitation or drought (the year 2009 at the study site was noticeably drier than the historical average) can increase the mortality of seedlings and saplings.

Interestingly, variation in the structure of the seedling and sapling communities in relation to cattle presence was less obvious than expected. Cattle presence explained only $2.1 \%$ of the community variance, even though the seedling communities in the sub-transects (fenced and unfenced) of transects 1 and 3 could be differentiated. These observed differences, which are illustrated in the RDA plot, may be due to other mechanisms, e.g., tree-cover composition, which varied between transects. It is important to note that other predators of seedlings, including invertebrates or rodents, could also underlie this result, as they could affect 


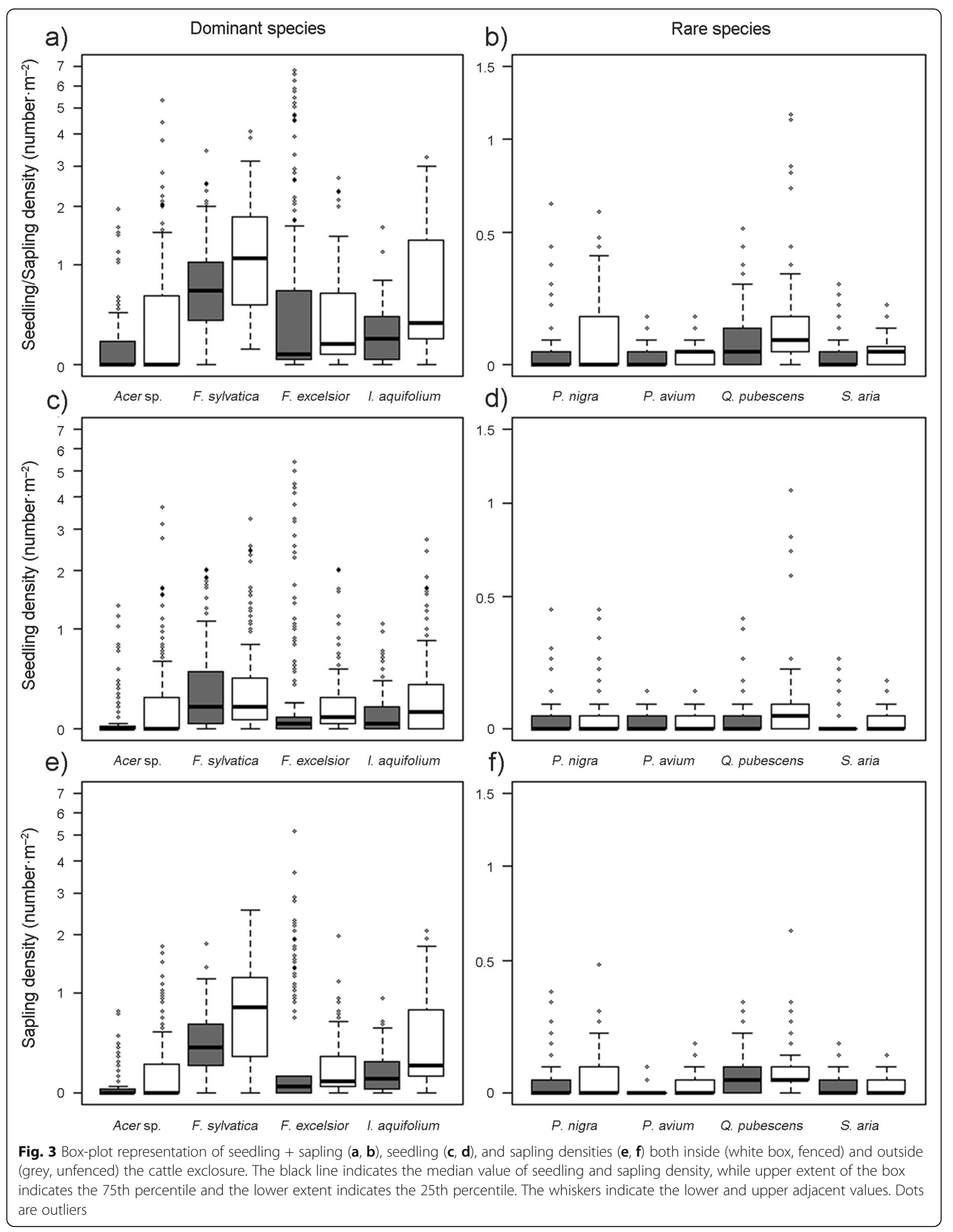



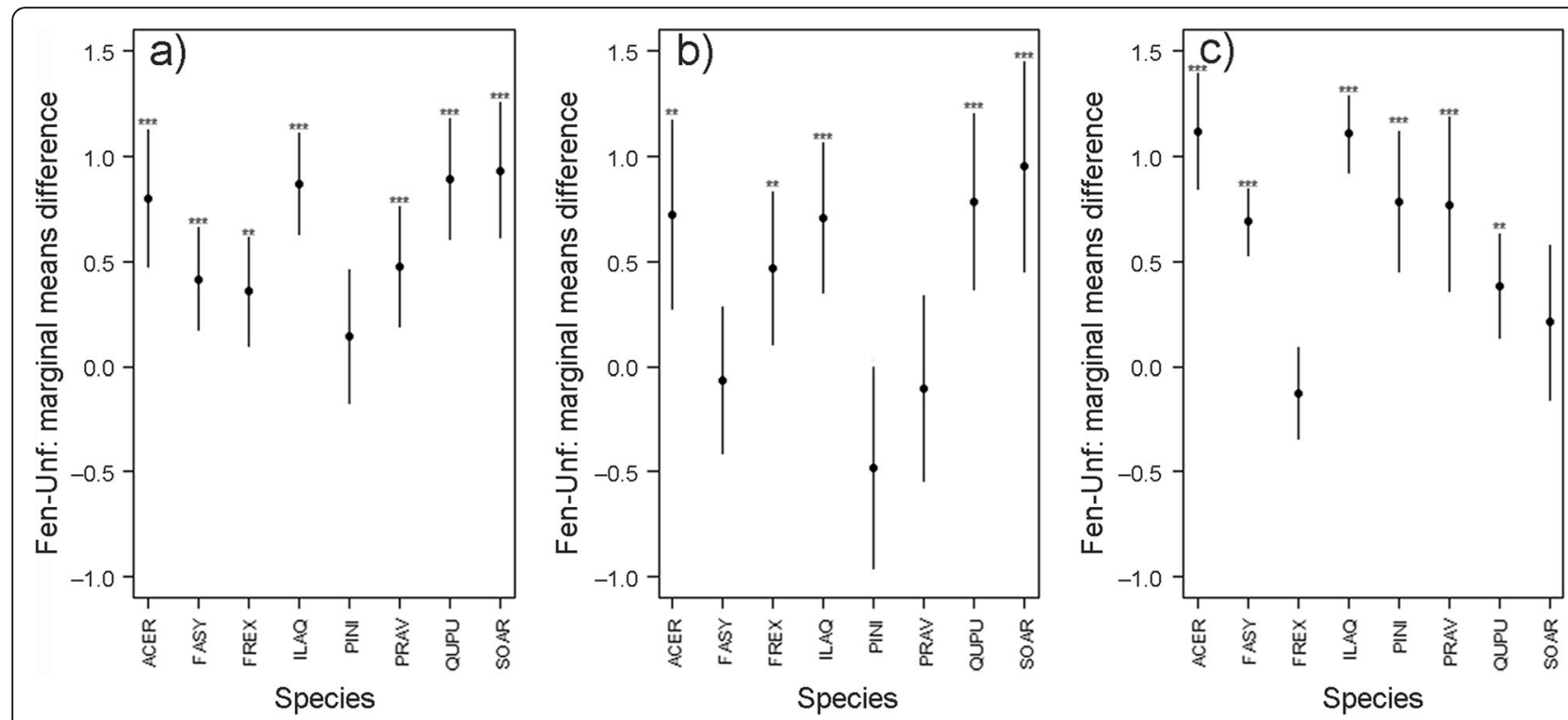

Fig. 4 Estimated differences in marginal means, including 95\% confidence intervals, for the (a) overall, (b) seedling and (c) sapling densities of each species with (Unf) and without the presence (Fen) of semi-feral cattle (Fen). Comparison of pairwise marginal mean (Fen-Unf): ${ }^{*} p<0.05,{ }^{* *}$ $p<0.01,{ }^{* * *} p<0.001$

all sub-transects in a similar manner because the wire mesh of this experiment does not exclude small animals. Complex insect-seedling interactions that are linked to herb cover and tree cover were reported, with the interactions differing between seedling tree species and involving different levels of herbivory, competition and facilitation (Vaz et al. 2019).

\section{Cattle presence alters tree regeneration and community composition}

Cattle exclosure had a highly positive effect on the sapling densities of six of the eight studied taxa (Fig. 4c), but a less significant positive effect on the seedling densities of five of eight taxa (Fig. 4b). Based on a wide body of literature (e.g., Dufour-Dror 2007), grazing is traditionally expected

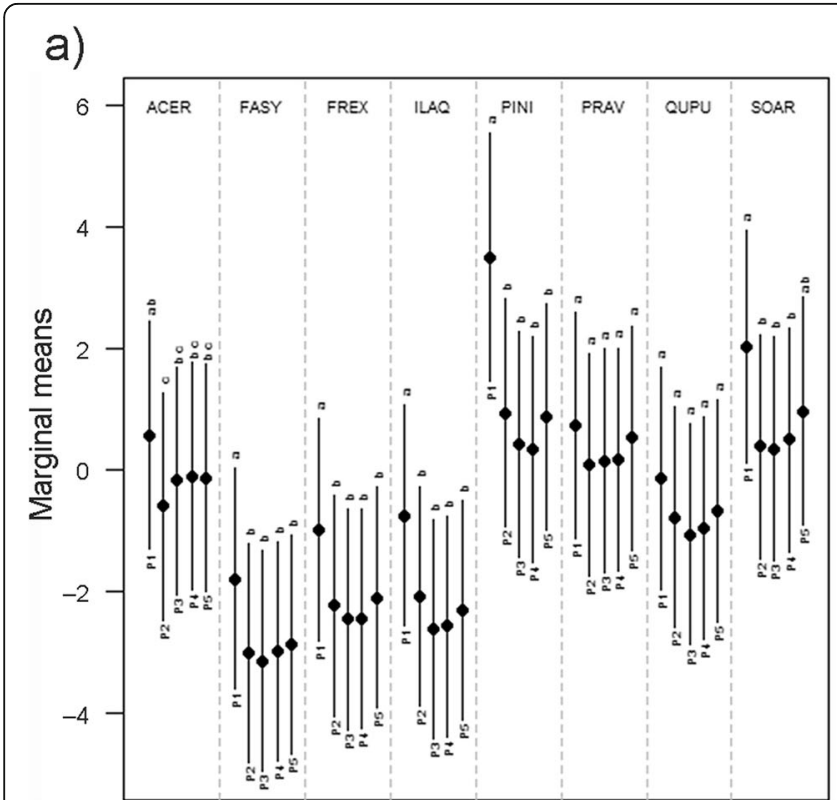

b)

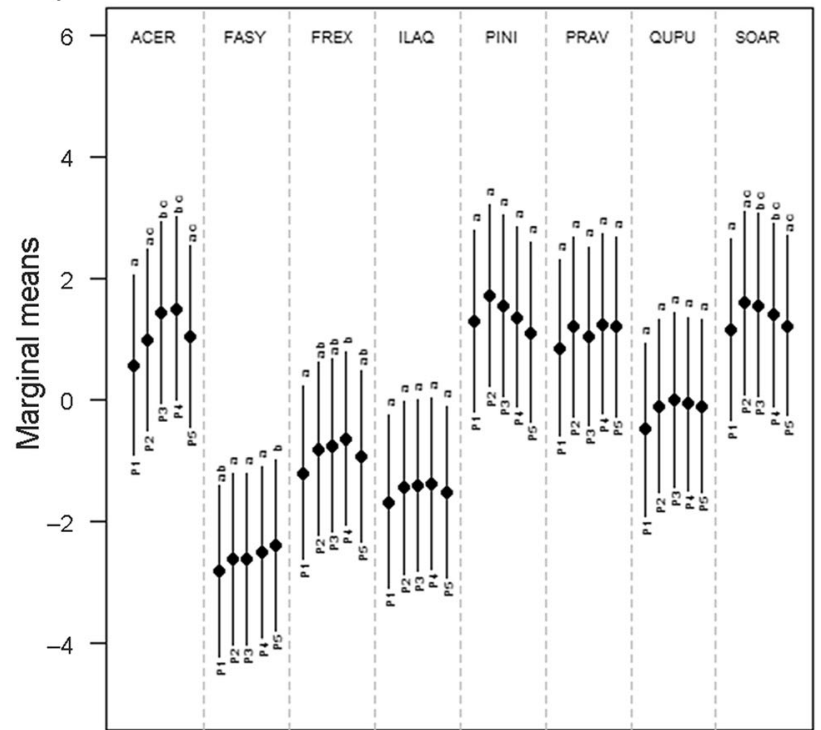

Fig. 5 Estimated marginal means, including 95\% confidence intervals, for the (a) seedling and (b) sapling densities of each species between seasons; P1: late winter, P2: early spring, P3: middle spring, P4: early summer, P5: early autumn. Within a species, periods marked with different letters significantly differ $(p<0.05)$ 
to negatively impact seedling and sapling densities. Although a positive effect of grazing on seedling density is less obvious, it has also been reported in some studies (e.g., González-Hernández and Silva-Pando 1996). For example, higher seedling emergence rates are generally related to suitable habitat characteristics, such as an available seedbed which results from trampling by livestock (Szwagrzyk et al. 2001). Cattle can thus exert opposing effects on young trees, either indirectly favouring seedling establishment through foraging for herbs and trampling moss cover, or directly reducing the abundance of certain species of plants through seedling grazing and sapling browsing. The overall effect of cattle presence on seedling density depends on the relative prevalence of both these processes, and can occasionally be negligible (meaning that both processes are in equilibrium), as observed here for Fagus and Prunus seedlings (Fig. 4b). Ultimately, the effect of cattle exclosure on sapling communities in old-growth Mediterranean forest was found to be taxon-specific (Fig. 4c).

Based on the presented research, the impact of cattle on forest regeneration was found to be taxonspecific. The observed variation in sensitivity to grazing probably resulted from animals' diet selection or foraging behaviour (Marquardt et al. 2009). A study that investigated the dietary composition of the cattle population in the same forest was examined in the present study showed that woody species form the bulk of the animals' diet, from ca. $70 \%$ in spring and summer to ca. $90 \%$ in winter (Bartolomé et al. 2011). This study suggests that the diet selection of these semi-feral cattle is closely related to which plants are available rather than animal preference. It has been found that the two main species consumed by cattle were Ilex and Fagus, mostly in a mixture with herbs (Travé 1993). Our results partially support this foraging behaviour. Ilex saplings and seedlings were strongly impacted by cattle presence (Fig. 4b and c), whereas only Fagus saplings were weakly affected (Fig. 4c). However, we reported that other species with lower canopy density were also highly impacted at their seedling (i.e. Acer, Quercus and Sorbus) or sapling stages (i.e. Acer, Pinus, Prunus). The results concerning Pinus confirm previous empirical research which found cattle to be a primary driver of black pine population dynamics (Chauchard et al. 2006). Differences in sensitivity to grazing may depend on species characteristics, such as compensatory growth ability after defoliation (Kupferschmid 2017). For example, Fraxinus has strong compensatory growth ability after defoliation, which may make these plants better suited to surviving grazing (Collin et al. 2000). The observed differences in tree regeneration under grazing pressure demonstrate that cattle presence promotes changes in tree composition, as has already been shown for other large herbivores in temperate forests (Putman 1996; Hester et al. 2000). As such, the presented results highlight the "biotic driver" role of herbivores in forest dynamics and composition (Bond 2005). Since the presented experiments concluded, the spring-summer cattle density in the area has been reduced from 0.46 to ca. 0.10 head.ha $^{-1}$ to maintain an equal density throughout the year. This reduction should favour the recruitment of Acer, Ilex, Quercus and Sorbus and, to a lesser extent, the recruitment of Fagus, Fraxinus and Prunus.

\section{Effects of season and cattle-season interactions on seedling and saplings densities}

Season affected the seedling densities of six species (Table 2 and Fig. 5a). However, this effect was not linked to the dry season, but rather to changes that occur during the late winter-early spring period (late March and early April). This finding was not in line with our working hypothesis, as we assumed that water stress during the dry summer months would increase mortality (Ibáñez and Schupp 2001; Pulido and Diaz 2005). Hence, our initial working hypothesis - that survival differences among species will be linked to summer water stress response - did not receive experimental support. Although the dry season did not influence seedling and/or sapling densities in this study, increased aridity in southern Europe, which is expected to occur due to climate change, remains a major issue for the conservation of mixed beech forests in the Mediterranean mountains (Cheaib et al. 2012).

Cattle presence and season do not interact to alter seedling and/or sapling densities (Table 2), although such an interaction was expected due to increased grazing pressure in the summer when herbs become rare or less palatable. This lack of interaction means that one driver's impact on regeneration does not depend on the other. This result is not in line with what has been previously reported, as multiple studies (e.g. Ibáñez and Schupp 2001) have identified a linkage between cattle presence and drought conditions on seedling survival.

The experimental setting and measurements applied in this study make it impossible to accurately distinguish effects that are derived from season (e.g., drought during summer months) and interannual variability in grazing intensity, which is inherent to the ecosystem. In this study, grazing intensity between seasons was not quantified. This was not because these types of measurements are impossible, as several methods for this type of quantification exist, for instance, dung measurements serve as a grazing proxy (e.g., Burkepile et al. 2016) or a camera trap can be 
used to capture images of animals feeding on seedlings and/or saplings (Rovero and Marshall 2009). Such methods would have enabled reliable measurements of grazing intensity at different times of the year, which could have helped us disentangle the effect of season from the effect of grazing intensity at a certain time of the year.

\section{Conservation issues}

Our regeneration monitoring during 7 yrs showed that (i) grazing and browsing by cattle exerts taxondependent effects on the early stages of tree regeneration and, surprisingly, (ii) seedling and sapling densities were not noticeably affected by the dry conditions of summer months. Therefore, our results indicate that cattle grazing is an important driver of seedling and sapling densities in this old-growth forest. Thus, managing a forest with or without the presence of cattle, a decision that depends on the conservation issue (rewilding, dung insect diversity, functionality, fire management, etc.), will have significant consequences for tree composition and dynamics. This means that any changes to the factor of livestock grazing will not have a neutral effect on the ecosystem based on the mass-ratio hypothesis (Grime 1998).

The decrease in cattle density since this study was performed might influence the regeneration of certain tree species and, in turn, the future composition of the tree community. However, such a trend might be balanced by increasing aridity, which is expected to occur in the Mediterranean in the near future (Giorgi and Lionello 2008; van Der Molen et al. 2011). Certain offset mechanisms can be expected to occur in the community once a certain drought threshold is exceeded. As such, the increased regeneration caused by reduced cattle pressure may be balanced by the impending increase in arid conditions. Greater aridity would favour drought-sensitive species in the Mediterranean mountain forests, with drought-resistant species becoming dominant as a result (Mendoza et al. 2009). As a result, certain species that are common to the Mediterranean, yet not currently abundant in the Massane forest holly oak (Quercus ilex) and white oak (Q. pubescens), may become noticeably more abundant in the area.

\section{Conclusion}

This seven-year study demonstrated that the presence of semi-feral cattle can influence the seedling/sapling community dynamics and structure of a Mediterranean mountain forest under current climatic conditions. The presented research found that grazing by cattle affected tree regeneration in a taxon-dependent manner. As such, the current exclusion of semi-feral cattle and other ungulates from most Euro-Mediterranean mountains would threaten the conservation of such socio-ecosystems, which have developed as a result of centuries of complex land uses. If we are to identify sustainable models for how to manage Mediterranean forest socio-ecosystems, forest pastoralism and climate change should be considered at the regional level.

\section{Nomenclature}

Flora Europaea (Tutin et al. 1976).

\section{Supplementary information}

Supplementary information accompanies this paper at https://doi.org/10. 1186/s40663-020-00222-7.

Additional file 1. Supplementary material S1: Location of the study area. Supplementary material S2: Mean seedling and sapling densities per $100 \mathrm{~m}^{2}$ outside (Unf) and inside (Fen) cattle exclosures between 2006 and 2012. Supplementary material S3: Estimated differences in marginal means for (a) overall, (b) seedling and (c) sapling densities of each species with (Unf) and without the presence of semi-feral cattle (Fen). The corresponding post-hoc test results (estimate, standard error, zratio and $p$-value) are shown.

\section{Abbreviations}

GLMM: Generalised Linear Mixed-effect Model; RDA: Redundancy Analysis

\section{Acknowledgments}

We warmly thank Nigel G Yoccoz and two anonymous reviewers for their constructive suggestions. We would like to thank the non-profit nature association Les Amis de la Massane for allowing us to work in the Massane Nature Reserve (MNR). We are also grateful to Joseph Garrigue and Jean-André Magdalou, the MNR rangers, for providing valuable information about the reserve surveys and management. We thank Loic Birker, Fanny Combet, Sarah Ivorra and Fabien Roiron for their help with the fieldwork.

\section{Legal statement}

All of the research work reported in this study was performed in accordance with all relevant legislation and guidelines.

\section{Authors' contributions}

C.C. conceived the study. X.F., S.C. and C.C. monitored the plant materials. X.F. and S.C. carried out the statistical analyses. X.F. wrote the first draft of the manuscript. S. C and C.C. provided feedback and completed the manuscript.

\section{Funding}

This study was supported by the Observatoire des Sciences de I'Univers OREME at Montpellier, France (INSU-CNRS).

\section{Availability of data and materials}

The materials described in the manuscript - including all relevant raw datawill be freely available upon request from the corresponding author.

Ethics approval and consent to participate

Not applicable.

Consent for publication

Not applicable.

\section{Competing interests}

The authors declare that they have no competing interests.

\section{Author details}

${ }^{1}$ Ecole Pratique des Hautes Etudes (EPHE), PSL University, 75014 Paris, France.

${ }^{2}$ Laboratoire d'Écologie des Hydrosystèmes Naturels et Anthropisés

(UMR5023 CNRS, Université Lyon 1, ENTPE), 69622 Villeurbanne, France. 
${ }^{3}$ Université de Lorraine, AgroParisTech, INRAE, UMR Silva, 54000 Nancy,

France.

\section{Received: 5 February 2019 Accepted: 26 February 2020}

Published online: 06 March 2020

\section{References}

Alejano R, Vázquez-Piqué J, Carevic F, Fernández M (2011) Do ecological and silvicultural factors influence acorn mass in holm oak (southwestern Spain)? Agrofor Syst 83:25-39

Arista M (1995) The structure and dynamics of an Abies pinsapo forest in southern Spain. Forest Ecol Manag 74:81-89

Bartolomé J, Plaixats J, Piedrafita J, Fina M, Adrobau E, Aixàs A, Bonet M, Grau J, Polo L (2011) Foraging behavior of Alberes cattle in a Mediterranean forest ecosystem. Rangeland Ecol Manag 64:319-324

Barton K (2019) MuMIn: Multi-Model Inference. R package version 1.43.6. https:// cran.r-project.org/web/packages/MuMIn/MuMIn.pdf. Accessed 05 Feb 2019

Bates D, Maechler M, Bolker B, Walker S (2015) Fitting linear mixed-effects models using Ime4. J Stat Softw 67:1-48

Bond WJ (2005) Large parts of the world are brown or black: a different view on the 'green world' hypothesis. J Veg Sci 16:261-266

Burkepile DE, Thompson DI, Fynn RWS, Koerner SE, Eby S, Govender N, Hagenah N, Lemoine NP, Matchett KJ, Wilcox KR, Collins SL, Kirkman KP, Knapp AK, Smith MD (2016) Fire frequency drives habitat selection by a diverse herbivore guild impacting top-down control of plant communities in an African savanna. Oikos 125:1636-1646

Carmona CP, Azcárate FM, Oteros-Rozas E, González JA, Peco B (2013) Assessing the effects of seasonal grazing on holm oak regeneration: implications for the conservation of Mediterranean dehesas. Biol Conserv 159:240-247

Casasùs I, Bernués A, Sanz A, Villalba D, Riedel JL, Revilla R (2007) Vegetation dynamics in Mediterranean forest pastures as affected by beef cattle grazing. Agric Ecosyst Environ 121:365-370

Castro J, Zamora R, Hodar JA, Gomez JM (2005) Alleviation of summer drought boosts establishment success of Pinus sylvestris in a Mediterranean mountain: an experimental approach. Plant Ecol 181:191-202

Chauchard S, Carcaillet C, Guibal F (2018) Fir expansion not controlled by moderate densities of large herbivores: a Mediterranean mountain grassland conservation issue. Ann For Sci 75:94

Chauchard S, Pille G, Carcaillet C (2006) Large herbivores control the invasive potential of nonnative Austrian black pine in a mixed deciduous Mediterranean forest. Can J For Res 36:1047-1053

Cheaib A, Badeau V, Boe J, Chuine I, Delire C, Dufrêne E, François C, Gritti ES, Legay M, Pagé C, Thuiller W, Viovy N, Leadley P (2012) Climate change impacts on tree ranges: model intercomparison facilitates understanding and quantification of uncertainty. Ecol Lett 15:533-544

Christensen JH, Christensen OB (2007) A summary of the PRUDENCE model projections of changes in European climate by the end of this century. Clim Chang 81:7-30

Cierjacks A, Hensen I (2004) Variation of stand structure and regeneration of Mediterranean holm oak along a grazing intensity gradient. Plant Ecol 173: 215-223

Collin P, Epron D, Alaoui-Sosse B, Badot P (2000) Growth responses of common ash seedlings (Fraxinus excelsior L.) to total and partial defoliation. Ann BotLondon 85:317-323

Dufour-Dror J-M (2007) Influence of cattle grazing on the density of oak seedlings and saplings in a Tabor oak forest in Israel. Acta Oecol 31:223-228

FAO (2018) State of Mediterranean forests. Food and agriculture Organization of the United Nations. Rome, Italy http://www.fao.org/3/CA2081EN/ca2081en. PDF.

Fortuny X, Carcaillet C, Chauchard S (2014) Land use legacies and site variables control the understorey plant communities in Mediterranean broadleaved forests. Agric Ecosyst Environ 189:53-59

Fortuny X, Chauchard S, Carcaillet C (2017) Confounding legacies of land uses and land-form pattern on the regional vegetation structure and diversity of Mediterranean montane forests. For Ecol Manag 384:268-278

Fournier T, Brossier B, Gauthier O, Carcaillet C (2012) Post-fire dynamics and spatial heterogeneity of woody debris associated with Pinus halepensis in an oak-pine Mediterranean ecosystem. Ecoscience 19:356-363

Fox J, Weisberg S (2019) An R companion to applied regression, third edition. Sage, Thousand Oaks, CA
Garrigue J, Magdalou J-A (2010) Climatologie de la Réserve Naturelle de la Massane - Analyse des données recueillies en 2010. Travaux de la Massane 45, Argelès-sur-Mer, France

Giorgi F, Lionello P (2008) Climate change projections for the Mediterranean region. Glob Planet Change 63:90-104

González-Hernández MP, Silva-Pando FJ (1996) Grazing effects of ungulates in a Galician oak forest (Northwest Spain). For Ecol Manag 88:65-70

Grime JP (1998) Benefits of plant diversity to ecosystems: immediate, filter and founder effects. J Ecol 86:902-910

Henkin Z, Gutman M, Aharon H, Perevolotsky A, Ungar ED, Seligman NG (2005) Suitability of Mediterranean oak woodland for beef herd husbandry. Agric Ecosyst Environ 109:255-261

Hester AJ, Edenius L, Buttenschon RM, Kuiters AT (2000) Interactions between forests and herbivores: the role of controlled grazing experiments. Forestry 73:381-391

Hulme PE, Borelli T (1999) Variability in post-dispersal seed predation in deciduous woodland: relative importance of location, seed species, burial and density. Plant Ecol 145:149-156

Ibáñez I, Schupp EW (2001) Positive and negative interactions between environmental conditions affecting Cercocarpus ledifolius seedling survival. Oecologia 129:543-550

Kolb PF, Robberecht R (1996) High temperature and drought stress effects on survival of Pinus ponderosa seedlings. Tree Physiol 16:665-672

Korner-Nievergelt F, Roth T, Von Felten S, Guélat J, Almasi B, Korner-Nievergelt $P$ (2015) Bayesian data analysis in ecology using linear models with R, BUGS, and Stan. Academic Press, Cambridge, MA

Krebs CJ (1999) Ecological methodology, 2nd edn. Cummings, Menlo Park, CA

Kuiters AT, Mohren GMJ, Van Wieren SE (1996) Ungulates in temperate forest ecosystems. For Ecol Manag 88:1-5

Kuiters AT, Slim PA (2002) Regeneration of mixed deciduous forest in a Dutch forest-heathland, following a reduction of ungulate densities. Biol Conserv 105:65-74

Kupferschmid AD (2017) Compensation capacity of central European tree species in response to leader shoot browsing. In: Menendez A, Sanz N (eds) Ungulates: Evolution. Diversity and Ecology. Nova Science Publishing, New York, NY, pp 1-63

Legendre P, Gallagher ED (2001) Ecologically meaningful transformations for ordination of species data. Oecologia 129:271-280

Lenth RV (2016) Least-squares means: the R package Ismeans. J Stat Softw 69:1-33

Marquardt S, Marquez A, Bouillot H, Beck SG, Mayer AC, Kreuzer M, Alzérreca H (2009) Intensity of browsing on trees and shrubs under experimental variation of cattle stocking densities in southern Bolivia. For Ecol Manag 258: 1422-1428

McEvoy PM, Flexen M, McAdam JH (2006) The effects of livestock grazing on ground flora in broadleaf woodlands in Northern Ireland. For Ecol Manag 225:39-50

Mendoza I, Zamora R, Castro J (2009) A seeding experiment for testing treecommunity recruitment under variable environments: implications for forest regeneration and conservation in Mediterranean habitats. Biol Conserv 142: 1491-1499

Nakagawa S, Schielzeth H (2013) A general and simple method for obtaining $R^{2}$ from generalized linear mixed-effects models. Met Ecol Evol 4:133-142

Oksanen J, Blanchet FG, Friendly M, Kindt R, Legendre P, McGlinn D, Minchin PR, O'Hara RB, Simpson GL, Solymos P, Stevens MHH, Szoecs E, Wagner H (2019) Vegan: community ecology package. R package version 2:5-5 https://cran.rproject.org/web/packages/vegan/index.html.

Öllerer K, Varga A, Kirby K, Demeter L, Biró M, Bölöni J, Molnár Z (2019) Beyond the obvious impact of domestic livestock grazing on temperate forest vegetation - a global review. Biol Conserv 237:209-219

Papachristou TG, Platis PD (2011) The impact of cattle and goats grazing on vegetation in oak stands of varying coppicing age. Acta Oecol 37:16-22

Perrin PM, Kelly DL, Mitchell FJG (2006) Long-term deer exclusion in yew-wood and Oakwood habitats in Southwest Ireland: natural regeneration and stand dynamics. For Ecol Manag 236:356-367

Piovesan G, Adams JM (2001) Masting behaviour in beech: linking reproduction and climatic variation. Can J Bot 79:1039-1047

Plieninger T (2007) Compatibility of livestock grazing with stand regeneration in Mediterranean holm oak parklands. J Nat Conserv 15:1-9

Plieninger T, Pulido FJ, Schaich H (2004) Effects of land-use and landscape structure on holm oak recruitment and regeneration at farm level in Quercus ilex L. dehesas. J Arid Environ 57:345-364 
Pulido FJ, Diaz M (2005) Regeneration of a Mediterranean oak: a whole-cycle approach. Ecoscience 12:92-102

Putman RJ (1996) Ungulates in temperate forest ecosystems: perspectives and recommendations for future research. For Ecol Manag 88:205-214

Ramirez $\mathrm{Jl}$, Jansen PA, Poorter L (2018) Effects of wild ungulates on the regeneration, structure and functioning of temperate forests: a semiquantitative review. For Ecol Manag 424:406-419

Rovero F, Marshall AR (2009) Camera trapping photographic rate as an index of density in forest ungulates. J Appl Ecol 46:1011-1017

Schermer E, Bel-Venner MC, Fouchet D, Siberchicot A, Boulanger V, Caignard T, Thibaudon M, Olliver G, Nicolas M, Gaillard JM, Delzon S, Venner S (2019) Pollen limitation as a main driver of fruiting dynamics in oak populations. Ecol Lett 22:98-107

Servant J (1970) Carte pédologique de France - Argelès-sur-Mer, Perpignan. In: Agronomique INdIR (ed) INRA. Service d'Etude des Sols, Montpellier, France

Smit C, Gusberti M, Müller-Schärer H (2006) Safe for saplings; safe for seeds? For Ecol Manag 237:471-477

Szwagrzyk J, Szewczyk J, Bodziarczyk J (2001) Dynamics of seedling banks in beech forest: results of a 10-year study on germination, growth and survival. For Ecol Manag 141:237-250

Tapper PG (1996) Long-term patterns of mast fruiting in Fraxinus excelsior. Ecology 77:2567-2572

Teich I, Cingolani AM, Renison D, Hensen I, Giorgis MA (2005) Do domestic herbivores retard Polylepis australis bitt. Woodland recovery in the mountains of Cordoba, Argentina? For Ecol Manag 219:229-241

Travé J (1993) Impact du Troupeau de Bovin sur la Réserve de la Massane. Travaux de la Massane 5, Argelès-sur-Mer, France

Tremblay J-P, Huot J, Potvin F (2007) Density-related effects of deer browsing on the regeneration dynamics of boreal forests. J Appl Ecol 44:552-562

Tutin TG, Heywood VH, Burges N, Valentine DH (1976) Flora Europaea. Cambridge University Press, Cambridge, UK

Vacchiano G, Hacket-Pain A, Turco M, Motta R, Maringer J, Conedera M, Drobyshev I, Ascoli D (2017) Spatial patterns and broad-scale weather cues of beech mast seeding in Europe. New Phytol 215:595-608

Van Der Moelen MK, Dolman AJ, Ciais P, Eglin T, Gobron N, Law BE, Meir P, Peters W, Phillips OL, Reichstein M, Chen T, Dekker SC, Doubkova M, Friedl MA, Jung M, Van Den Hurk BJJM, De Jeu RAM, Teuling AJ, Van Der Werf GR, Wang G (2011) Drought and ecosystem carbon cycling. Agri For Meteo 151: $765-773$

Vaz PG, Bugalho MN, Fedriani JM, Branco M, Lecomte X, Nogueira C, Caldeira MC (2019) Unravelling associations between tree-seedling performance, herbivory, competition, and facilitation in high nature value farmlands. J Env Manag 232:1066-1074

Wassie A, Sterck FJ, Teketay D, Bongers F (2009) Effects of livestock exclusion on tree regeneration in church forests of Ethiopia. For Ecol Manag 257:765-772

\section{Submit your manuscript to a SpringerOpen ${ }^{\circ}$ journal and benefit from:}

- Convenient online submission

- Rigorous peer review

- Open access: articles freely available online

- High visibility within the field

- Retaining the copyright to your article

Submit your next manuscript at $\boldsymbol{\nabla}$ springeropen.com 